\title{
Influence of Environmental Stressors on the Microbiota of Zebra Mussels (Dreissena polymorpha)
}

\author{
Prince P. Mathai ${ }^{1}$ - Jonathan H. Bertram ${ }^{1}$ - Soumesh K. Padhi ${ }^{2}$. Vikash Singh ${ }^{3}$ - Isaiah E. Tolo $^{2}$ - Alexander Primus ${ }^{3}$. \\ Sunil K. Mor ${ }^{3} \cdot$ Nicholas B. D. Phelps ${ }^{2} \cdot$ Michael J. Sadowsky ${ }^{1,4,5}$
}

Received: 20 July 2020 / Accepted: 11 November 2020 / Published online: 26 November 2020

(C) The Author(s) 2020

\begin{abstract}
Host-associated microbiota play a critical role in host fitness by providing nutrition, enhancing digestion capabilities, and by providing protection from pathogens. Here, we investigated the effects of two environmental stressors, temperature, and salinity, on the microbiota associated with zebra mussels (ZMs), a highly invasive bivalve in North America. To examine this in detail, lake-collected ZMs were acclimated to laboratory conditions, and subjected to temperature and salinity stress conditions. The impact of these stressors on the diversity, composition, and dynamics of ZM-associated microbiota were assessed by using amplicon- and shotgun-based sequencing, and qPCR-based approaches. Elevated temperature was found to be the primary driver of ZM mortality, although salinity alone also increased its likelihood. Stressor-induced ZM mortality, which ranged between 53 and $100 \%$, was concomitant with significant increases in the relative abundance of several genera of putative opportunistic pathogens including Aeromonas. These genera were only present in low relative abundance in ZMs obtained from the control tank with $0 \%$ mortality. Shotgun sequencing and qPCR analyses indicated that the relative and absolute abundances of pathogenic Aeromonas species (particularly A. veronii) were significantly greater in temperature-induced dead ZMs. Taken together, our results show that environmental stress, especially elevated temperature $\left(>25^{\circ} \mathrm{C}\right)$, is associated with the rapid mortality of $\mathrm{ZMs}$ as well as the proliferation of putative opportunistic bacterial pathogens.
\end{abstract}

Keywords Zebra mussels $\cdot$ Stress $\cdot$ Temperature $\cdot$ Salinity $\cdot$ Microbial communities $\cdot$ Pathogens $\cdot$ Invasive species

\section{Introduction}

The dreissenid Dreissena polymorpha, commonly known as the zebra mussel (ZM), is among the most successful aquatic

Prince P. Mathai and Jonathan H. Bertram contributed equally to this work.

Michael J. Sadowsky

sadowsky@umn.edu

1 BioTechnology Institute, University of Minnesota, 1479 Gortner Ave., 140 Gortner Labs, St. Paul, MN 55108, USA

2 Department of Fisheries, Wildlife, and Conservation Biology, University of Minnesota, St. Paul, MN, USA

3 Department of Veterinary Population Medicine, University of Minnesota, St. Paul, MN, USA

4 Department of Soil, Water, and Climate, University of Minnesota, St. Paul, MN, USA

5 Department of Plant and Microbial Biology, University of Minnesota, St. Paul, MN, USA animals in the Anthropocene. These bivalve mollusks, native to the Caspian Sea, were introduced to Lake Erie (USA) in the 1980s, most likely via ballast water discharged from transatlantic shipping vessels [1]. Since this time, these invasive suspension-feeders have proliferated in thousands of waterbodies in the Northeastern and Midwestern USA [2]. Strategies to contain the spread and reduce the resultant damage due to ZM proliferation have generally been unsuccessful. Thus far, ZMs have been discovered as far south as Texas and as far west as California, progressively expanding into new territories and climate regimes [3, 4]. The pervasiveness, behavior, and resiliency of ZMs have secured them a role as an "ecological engineer" in many aquatic ecosystems [5].

ZMs have several physiological traits that contribute to their success as an invasive species, including a high suspension-feeding capacity, high fecundity, and an affinity for hard substrates such as shells of native mussel species $[6$, 7]. ZMs alter trophic systems by removal of plankton from the water column and deposition on the bottom of the waterbody [8]. Associated direct ecosystem changes include a decrease in 
zooplankton and phytoplankton, an increase in benthic primary productivity, and an increase in benthic microbial biodiversity [9-12]. ZMs indirectly affect piscivorous fish populations and increase light penetration, thus increasing the littoral zone of a waterbody and enhancing the growth of attached benthic macrophytic algae [13].

Despite successful establishment in some systems, introduced bivalves, like ZMs, are susceptible to environmental extremes and climate variation -conditions many native species are able to endure $[14,15]$. For instance, over $99 \%$ of an invasive Asian clam (Corbicula fluminea) was extirpated from a river in Southern USA because of drought [16]. A few studies have addressed the impact of environmental perturbations on ZMs, specifically that they suffer physiological stress and acute mortality at temperatures greater than 30-33 ${ }^{\circ} \mathrm{C}[17,18]$ and prefer salinities less than 4 ppt $[19,20]$. Mollusks are both poikilothermic and ectothermic, and thus their body temperature is variable and dependent on the water in which they reside. Both absolute temperatures and abrupt temperature changes can significantly impact rates of metabolism, immunological function, and disease susceptibility. Like other bivalves, ZMs harbor a large number of microbiota [21], some of which are postulated to play major roles in their growth and survival. It seems likely that changes in environmental factors (e.g., temperature) would also impact the composition of microbial communities associated with such organisms, either directly or indirectly. Therefore, given the pivotal role of ZMs in aquatic ecosystems and in light of changing climate regimes, it is crucial to understand the relationships between ZMs and how their associated microbiota respond to stressors, and environmental perturbations. This information may also be useful for future biocontrol efforts.

The objective of this study was to understand how ZMs and their associated microbiota respond to temperature and salinity stress. We hypothesized that these stressors would alter the composition of ZM-associated microbial communities potentially leading to the outgrowth of adapted opportunistic pathogens which induce ZM mortality. To test this hypothesis, ZMs were harvested from a natural lake environment, acclimated to laboratory conditions in aquaria, and subjected to temperature and salinity stress conditions over a period of 6 weeks. The impact of these stressors on ZM-associated microbial communities was examined by using a combination of amplicon- and shotgun-based sequencing, and via quantitative PCR-based approaches.

\section{Methods}

\section{Field Sampling}

Prior to commencing this study, a permit was obtained from the Minnesota Department of Natural Resources (MNDNR) to collect, possess, and transport ZMs from lakes with established dreissenid populations. Over 2,500 ZMs were collected on September 5, 2018 within a $30-\mathrm{m}^{2}$ area of Gull Lake in Minnesota (USA) (GPS coordinates: 46.3963529, 94.3686372). Mussels (1.8 to 3.5-cm length) were collected within depths of $0.2-1.0 \mathrm{~m}$ from hard surfaces including stones, rocks, and clusters of mussels (druses).

Water temperature, $\mathrm{pH}$, and dissolved oxygen concentrations were measured at time of collection using a handheld thermometer (Taylor; Oak Brook, IL, USA), pH meter (Vantakool; Elizabeth, CO, USA), and a MW 600 Smart DO meter (Milwaukee Instruments; Milwaukee, WI, USA), respectively. At the time of $\mathrm{ZM}$ collection, the lake water temperature was $21.7 \pm 0.6^{\circ} \mathrm{C}$, had a pH of $8.86 \pm 0.04$ and dissolved oxygen concentration was $7.2 \pm 0.2 \mathrm{mg} / \mathrm{L}$. The ZMs were kept in lake water in sterile $1 \mathrm{~L}$ plastic containers (Nalgene; Rochester, NY, USA) and transported on ice to the invasive species containment facility (Minnesota Aquatic Invasive Species Research Center; [MAISRC], University of Minnesota; Saint Paul, MN), within 24 h of collection.

\section{Tank Setup and Maintenance}

All ZM tank experiments were conducted in a biosafety level-2 lab located within the MAISRC containment facility at the University of Mnnesota. The ZMs were initially transferred to a holding tank (110 L capacity, $30 \mathrm{~cm} \times 45 \mathrm{~cm} \times 85 \mathrm{~cm})$ containing a 4:1 mixture of well water and filtered lake water, sourced from the sampling site. After $24 \mathrm{~h}$, the ZMs were divided into six 110-L tanks (A-F; 5 experimental tanks and 1 control). During tank division, deceased, and visibly moribund ZMs were removed. Individual ZM counts ranged between 189 and 260 per tank, and ZMs were subdivided in glass Petri dishes (90$\mathrm{mm}$ diameter $\times 15$-mm height) into groups of approximately 20 individuals. Each experimental tank contained a 4:1 mixture of well water and pooled lake water, kept at $17 \pm 1{ }^{\circ} \mathrm{C}$. Lake water was pooled from four lakes (Gull-Crow Wing County, ComoRamsey County, and Harriet and Bde Maka Ska-Hennepin County) to obtain diverse bacterioplankton communities, and filtered through sterile double cheese cloth to remove large debris. Each tank was gently aerated, maintained in an ambient room temperature of $17 \pm 1{ }^{\circ} \mathrm{C}$ and illuminated under a photoperiod of $12 \mathrm{~h}$ light: $12 \mathrm{~h}$ dark cycle. ZMs were fed every day with 5-ml PhytōChrōm (approximately 200 million phytoplankton cells per mL, particle size: $1-30 \mu \mathrm{m}$, Brightwell Aquatics; Fort Payne, AL, USA) per $110 \mathrm{~L}$ of tank water, as per labeling instructions. The feed comprised six species of marine algae, which included Haematococcus sp., Nannochloroposis sp., Tetraselmis sp., Isochrysis sp., Pavlova sp., and Thalassiosira species. We postulated that the wide range of food particle size $(1-30 \mu \mathrm{m})$ would be more reflective of a natural habitat, allowing both selection and rejection of particles during ZM filtration feeding. 
Water chemistry (temperature, $\mathrm{pH}$, and $\mathrm{DO}$ ) were monitored daily throughout the course of this experiment (Fig. $\mathrm{S} 1$ ), as described previously. In addition, salinity and total ammonia nitrogen (TAN) concentrations were measured daily, with a portable salinity refractometer (Agriculture Solutions; Strong, ME, USA) and an ammonia test kit (API; Chalfont, PA, USA), respectively. Every 2-3 days, approximately $10 \%$ of the tank water was discarded and replaced with fresh well water, so as to maintain TAN concentrations below $0.25 \mathrm{mg} / \mathrm{L}$.

During the acclimation period, infirm, and deceased ZMs, identified by visual cues and motor response, were removed. The health status of the ZMs was assessed by disturbing the water near an individual ZM. Healthy ZMs would quickly retract their siphons and close their shells upon disturbance. Infirm ZMs that were found to suffer mortality shortly thereafter exhibited a slowed response, and deceased ZMs exhibited no motor response. The acclimation phase lasted for 14 days (temperature $17 \pm 1^{\circ} \mathrm{C} ; 12 \mathrm{~h}$ light: dark cycle; with daily feeding regiment), after which experimental stressors were initiated in 5 tanks (A, B, C, D, and E).

\section{Application of Stressors in Experimental Tanks}

After the acclimation phase, the stressors (temperature and salinity) were slowly increased during the ramp-up phase, which lasted between 10 and 14 days, depending on the tank. The temperature stressor limits (medium temp: $26^{\circ} \mathrm{C}$ and high temp: $32{ }^{\circ} \mathrm{C}$ ) were selected based on sublethal and lethal temperature-induced mortality limits determined in prior studies [22]. A salinity stressor limit of $13.5 \mathrm{ppt}$ was selected based on the range of saline habitats encountered by ZMs in North America and those of ancestral habitats [18, 23]. Moreover, since environments supporting the growth of ZMs are dynamic, an alternating temperature scenario method was imparted to compare temperature accumulation damage and provide a secondary signal for daily circadian rhythms.

The water temperature in tanks $\mathrm{A}, \mathrm{B}, \mathrm{D}$, and $\mathrm{E}$, was increased at approximately $1{ }^{\circ} \mathrm{C}$ per day using two 200-W digital aquarium heaters per tank (Aquatop; Brea, CA, USA), whereas the salinity in tanks $\mathrm{C}$ and $\mathrm{D}$ was increased by approximately 2 ppt every 2 days by adding an aquarium salt formulation (Instant Ocean; Blacksburg, VA, USA). After reaching the final set point $\left(\operatorname{tank} \mathrm{A}: 32{ }^{\circ} \mathrm{C}, 1.5 \mathrm{ppt}\right.$; tank B: $32{ }^{\circ} \mathrm{C}, 13.5 \mathrm{ppt}$; tank C: $17{ }^{\circ} \mathrm{C}, 13.5 \mathrm{ppt}$; tank D: $32^{\circ} \mathrm{C}, 1.5$ ppt; tank E: $26{ }^{\circ} \mathrm{C}, 1.5 \mathrm{ppt}$ ), constant conditions in all tanks were maintained, except for tank A where heat was provided for only $16 \mathrm{~h}$ each day. These conditions were maintained for 28 days or until the conclusion of the experiment. Tank F (control) was maintained at room temperature $\left(17 \pm 1{ }^{\circ} \mathrm{C}\right)$, with no salinity added $(1.5 \mathrm{ppt})$, throughout the duration of this experiment.

\section{Sample Collection and Processing}

ZMs were periodically collected for microbial community analysis by removing at least 5 randomly selected, visibly healthy, "live" individuals from each tank per timepoint (Fig. S2). In addition, dead ZMs, identified by visual cues and lack of motor response, were collected during daily monitoring, to limit the growth of saprophytic bacteria in dead or dying ZMs. Upon collection, all ZMs were immediately stored at $-80{ }^{\circ} \mathrm{C}$ for later processing. Prior to processing, the frozen ZMs were thawed to room temperature, and the exterior shell of each individual was gently scrubbed with $70 \%$ ethanol using a toothbrush. The shell was opened by making an incision to the adductor muscle using a sterile razor blade. The internal tissue was aseptically transferred to a 2-ml microcentrifuge tube containing $500 \mu \mathrm{l}$ of $1 \mathrm{x}$ phosphate buffered saline $(\mathrm{pH} \mathrm{7.0)}$ and vortexed for $1 \mathrm{~min}$. The tissue was homogenized with a sterile glass tissue grinder for $1 \mathrm{~min}$ and tubes were vortexed for an additional $5 \mathrm{~min}$. The homogenate was centrifuged at low speed $(500 \times g)$ for $10 \mathrm{~min}$ to separate larger cell debris from the supernatant. The resulting supernatant was stored at $-80^{\circ} \mathrm{C}$ until used.

Water samples $(100 \mathrm{ml})$ were collected from each tank (total $=23$; sampling timeline depicted in Fig. S5) and filtered through 5- $\mu \mathrm{m}$ mixed cellulose filters (MF-Millipore; Darmstadt, Germany), followed by $0.22-\mu \mathrm{m}$ filters (MFMillipore). Both the MF filters were pooled together and transferred to a $15-\mathrm{ml}$ tube and $4 \mathrm{ml}$ of $0.01 \%$ sodium pyrophosphate buffer, $\mathrm{pH} 7.0$, containing $0.2 \%$ Tween 20 , was added. Tubes were vortexed for $3 \mathrm{~min}$, centrifuged at $13,000 \times \mathrm{g}$ for $5 \mathrm{~min}$, and the pellets were stored at $-20^{\circ} \mathrm{C}$.

DNA was extracted from thawed frozen supernatant of ZM tissues and cell pellets of water samples using the DNeasy PowerSoil Kit (Qiagen; Hilden, Germany) as per manufacturer's instructions. DNA concentrations were measured using Qubit 2.0 Fluorometer (ThermoFisher Scientific; Waltham; MA, USA). The extracted DNA samples were stored at -20 ${ }^{\circ} \mathrm{C}$ until further analysis.

\section{Amplicon Sequencing, Bioinformatics, and Statistical Analysis}

DNA samples $(n=405)$ were sequenced at the University of Minnesota Genomics Center (UMGC; Minneapolis, MN) by using universal primers: 515f (5'-GTGCCAGC M G C C GCGGTA A - 3') a n d 806 r ( 5' GGACTACHVGGGTWTCTAAT-3') targeting the V4 region of the 16S rRNA gene as described elsewhere [24]. Bar-coded sequencing was performed on the MiSeq platform (Illumina, San Diego, CA) using a $2 \times 300$-bp paired end protocol. All fastq files were deposited in the NCBI Sequence Read Archive under BioProject accession number PRJNA645687. 
Sequences were analyzed using QIIME v.1.8.0 [25]. Illumina adapters and low quality regions $(<\mathrm{Q} 30)$ were removed using Trimmomatic v. 3.2 [26]. Reads with less than $75 \%$ of the total amplicon length were discarded and highquality reads were joined in pandaseq using the fastqjoin script $[27,28]$. Chimeras were identified using UCHIME v. 6.1 [29]. A naïve Bayesian classifier was used to classify sequences against the RDP training set v. 9 at $80 \%$ bootstrap confidence score [30]. Open-reference operational taxonomic units (OTUs) were clustered at 3\% dissimilarity using UCLUST and compared against the SILVA v.132 16S rRNA database using PyNast [31-33]. OTU counts were rarefied to 10,000 sequences per sample for statistical analysis.

Alpha diversity measures were calculated using Good's coverage, observed OTUs, Chao1, Shannon's H and Simpson's E indices. Bray-Curtis dissimilarity matrices were used for principal coordinate analysis (PCoA). These matrices were also used to assess statistical significance of beta diversity between different $\mathrm{ZM}$ groups by using permutational multivariate analysis of variance (PERMANOVA) [34] using the Adonis function in the R package vegan [35] with 999 permutations. The PERMDISP function was used to examine whether the dispersions between groups were significant [36]. Redundancy analysis (RDA) was performed to determine which taxa best explained ZM mortality using XLSTAT Ecology v 19.6 (Addinsoft; New York, NY USA). In addition, taxa that were overrepresented in dead ZMs (tanks A-E) were identified (vs. control tank F) using linear discriminant analysis effect size (LEfSe) analysis [37]. A $p$ value less than 0.05 was considered to indicate statistical significance for all tests.

\section{Shotgun Metagenomic Sequencing and Analysis}

A total of 28-pooled ZM tissue samples (10 individuals per timepoint) were obtained from the six tanks and processed for shotgun sequencing as described above. The frozen homogenates (stored in $-80^{\circ} \mathrm{C}$ ) were freeze-thawed three times, and centrifuged at $2,896 \times g$ for $25 \mathrm{~min}$ at $4{ }^{\circ} \mathrm{C}$. The supernatant was treated with TURBO ${ }^{\mathrm{TM}}$ DNase (Ambion; Austin, TX, USA) and RNase A (ThermoFisher Scientific) for $1 \mathrm{~h}$ at 37 ${ }^{\circ} \mathrm{C}$ to reduce host nucleic acid interference. Nucleic acids were extracted using QIAamp MinElute Virus Spin Kit (Qiagen) by following manufacturer's instruction with slight modification. Linear acrylamide was used as a carrier of nucleic acids instead of carrier RNA. The extracted nucleic acids were submitted to the UMGC for library preparation and sequencing. Library preparation was completed using the dual-indexed Stranded Total RNA Pico Mammalian kit, according to manufacturer instructions (Clontech, a Takara Bio Company, CA, USA). Libraries were normalized according to the median fragment size measured by Tape Station 2.0 (Agilent) and library concentration measured by Qubit. Sequencing was performed on the HiSeq 2500 platform (Illumina) using a 2 $\times 125$-bp paired end protocol. After automated cluster generation, the genomic sequence reads (fastq) files were obtained for further analysis. Species-level taxonomic profiling was performed using Kraken, which unambiguously classifies shotgun metagenomic reads based on the analysis of shared k-mers between input reads and pre-compiled database of genomes [38]. All fastq files were deposited in the NCBI Sequence Read Archive under BioProject accession number PRJNA645687.

\section{Quantitative PCR}

The total bacterial 16S rRNA and cytotoxic enterotoxin (act) genes in ZM samples were quantified using primer sets: $515 \mathrm{f}$ (5'-GTGCCAGCMGCCGCGGTAA-3') and 806r (5'GGACTACHVGGGTWTCTAAT-3') [39], and AHCF (5'GAGAAGGTGACCACCAAGAACA-3') and AHCR (5'AACTGACATCGGCCTTGAACTC-3') [40], respectively. The qPCRs were done using a StepOnePlus Real-Time PCR System (Applied Biosystems, Foster City, CA, USA). The reaction mixture $(12 \mu \mathrm{l})$ contained iTaq Universal SYBR Green Supermix (Bio-Rad, Hercules, CA, USA), $500 \mathrm{nM}$ each forward and reverse primer, and $6 \mu$ DNA template. PCR was performed, in duplicate, under the following conditions: initial denaturation at $95^{\circ} \mathrm{C}$ for $10 \mathrm{~min}$, followed by 40 cycles of $95{ }^{\circ} \mathrm{C}$ for $15 \mathrm{~s}$ and either $55^{\circ} \mathrm{C}$ (total $16 \mathrm{~S}$ rRNA gene) or $60^{\circ} \mathrm{C}$ (act gene) for $1 \mathrm{~min}$. Each qPCR run included DNA standards and no-template controls. Melt-curve analysis was performed after each run to confirm reaction specificity. The threshold cycle value was determined using the StepOnePlus ${ }^{\mathrm{TM}}$ Software v2.3 (Applied Biosystems).

\section{Results}

\section{Stressor-Induced ZM Mortality}

Elevated temperature was the primary driver of ZM mortality, although salinity increased the likelihood of mortality as well (Fig. 1, Table S1). Heat stress to ZM appeared to accumulate during the acclimation and experimental phase when thermal stress was applied. ZM mortality increased dramatically as the temperatures reached $30{ }^{\circ} \mathrm{C}$ in tanks $\mathrm{D}, \mathrm{B}$, and A. Based on preltrial observations, the rate of mortality was considered severe if greater than $2.5 \%$ of the tank population was lost daily. The ZMs in tank D (high temp) withstood temperatures greater than $30{ }^{\circ} \mathrm{C}$ for 2 days, however $95 \%$ were dead by the third day, resulting in early experimental termination. Similarly, over $33 \%$ of the ZMs within tank B (high temp and high salinity) suffered mortality within two experimental days of the water temperature surpassing $30^{\circ} \mathrm{C}$, 
Fig. 1 Tank experiments demonstrating the effect of water temperature and salinity on $\mathrm{ZM}$ survival. Dashed vertical lines indicate the end of the acclimation phase (14 d) and the start of experimental phase ( 28 days) in tanks A-E
Tank A

(fluctuating temperature + low salinity)

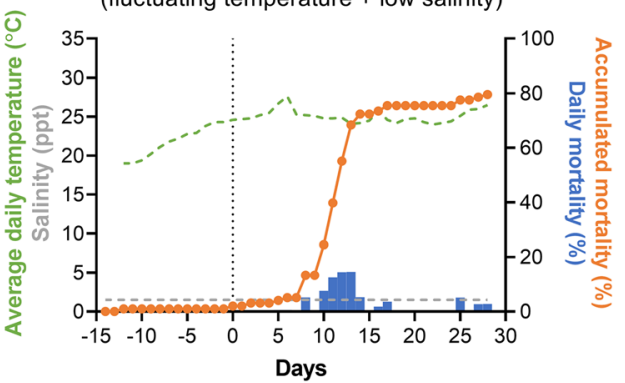

Tank C

(low temperature + high salinity)

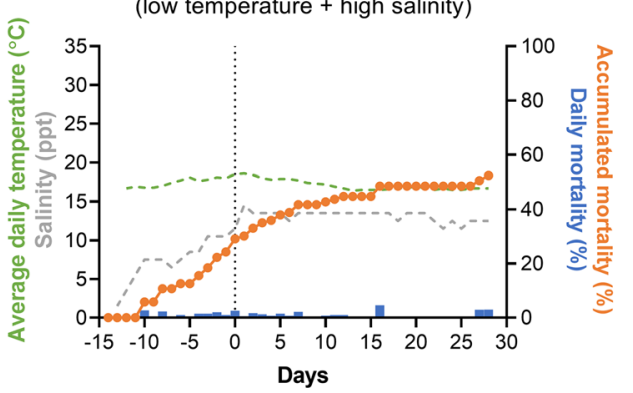

Tank E

(medium temperature + low salinity)

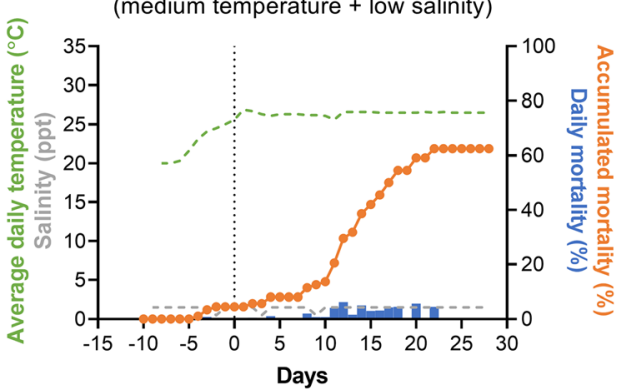

Tank B

(high temperature + high salinity)

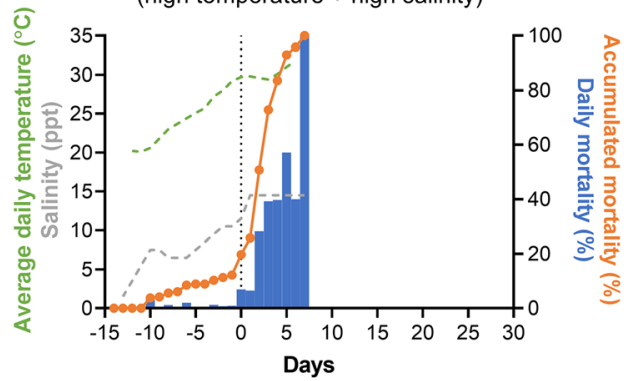

Tank D

(high temperature + low salinity)

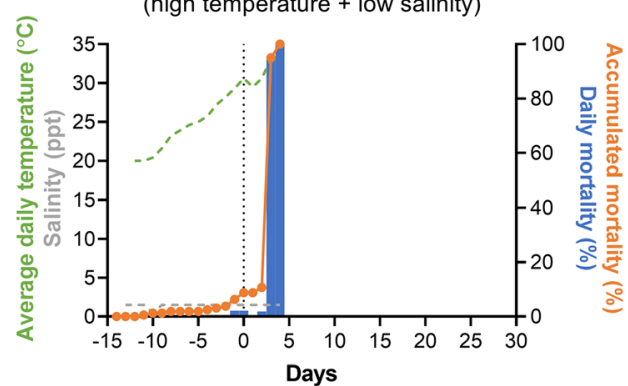

Tank F - Control

(low temperature + low salinity)

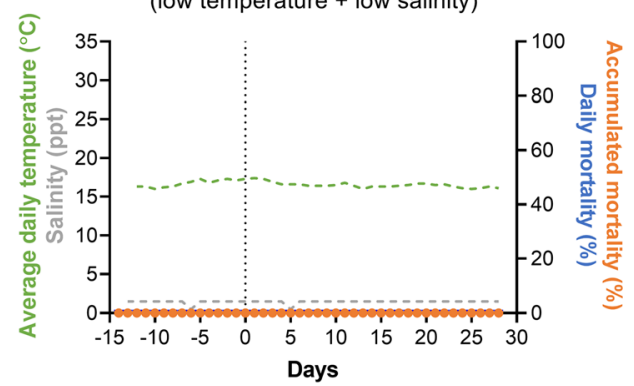

with the remainder being lost by day 7 . The fluctuating temperature condition in tank A increased mortality after 10 days (at experimental temp), although the rate of loss decreased after 14 days and remained low for the duration of the experiment. Tank E (medium temp) reached a maximum temperature of $26{ }^{\circ} \mathrm{C}$, and accumulated thermal stress at a much lower rate: after 11 days, the rate of $\mathrm{ZM}$ loss increased from $0.5 \% \pm 0.6 \% \mathrm{ZMs}$ per day to $3.1 \% \pm 2.6 \% \mathrm{ZMs}$ per day and remained low for the duration of the experiment. While tank $\mathrm{C}$ was kept at room temperature $\left(17 \pm 1{ }^{\circ} \mathrm{C}\right)$, it had the same salinity level as tank B (13.5 ppt). A steady and low mortality rate $(1.2 \% \pm 0.8 \%$ per day) began as soon as the salinity was increased, but death rate remained consistent for the first 12 days of the experiment, before dropping to $1.0 \% \pm$ $1.6 \%$ deaths per day for the remaining 16 days. There was no ZM mortality in tank F (control) during the acclimation or experimental phases. The treatments employed were successful in stressing ZMs, and the proportion of dead ZMs in each tank at the end of the experiment were as follows: tank A (fluctuating temp) 79.6\%, tank B (high temp and high salinity) $100 \%$, tank C (high salinity) $52.4 \%$, tank D (high temp) 100\%, tank E (medium temp) $70.5 \%$, and tank F (control) $0 \%$.

\section{Effect of Stressors on Microbiota Associated with ZMs}

High-throughput DNA sequencing of 405 samples generated approximately 31 million paired-end reads, of which $88 \%$ of sequences passed the quality filtration steps. Seven samples were removed from subsequent analyses as they did not meet the minimum cutoff of 10,000 sequences per sample. Sequence analysis found a range of 244 to 1316 OTUs among all samples, with a mean \pm standard deviation Good's coverage of $97.1 \% \pm 1.0 \%$.

When measured by the Shannon index, live ZMs from tank $\mathrm{F}$ had significantly greater alpha diversity than did the dead ZMs from experimental tank D $(p=0.001)$ (Table 1). In all the experimental tanks, dead ZMs were less diverse compared to live ZMs (Table 1). A reduction in diversity was also observed 
Table 1 Coverage and alpha diversity indices for microbial communities among ZM samples collected during the experimental phase, consolidated by tank and mortality status

\begin{tabular}{|c|c|c|c|c|c|c|c|}
\hline Tank & Status & $n$ & Good's coverage $(\%)$ & Observed OTUs & Shannon's H & Chao1 & Simpson's E \\
\hline \multirow[t]{2}{*}{ A } & Live & 38 & $96.7 \pm 1.1$ & $759 \pm 224^{\mathrm{A}}$ & $5.87 \pm 1.61^{\mathrm{A}}$ & $1311 \pm 369^{\mathrm{A}}$ & $0.030 \pm 0.031^{\mathrm{A}}$ \\
\hline & Dead & 28 & $96.6 \pm 1.1$ & $616 \pm 229^{\mathrm{ABC}}$ & $5.00 \pm 1.28 \mathrm{ABC}$ & $1307 \pm 372^{A}$ & $0.021 \pm 0.013^{\mathrm{A}}$ \\
\hline \multirow[t]{2}{*}{ B } & Live & 20 & $97.2 \pm 0.6$ & $615 \pm 99 \mathrm{ABC}$ & $5.71 \pm 0.45^{\mathrm{AB}}$ & $1187 \pm 178^{\mathrm{AB}}$ & $0.024 \pm 0.016^{\mathrm{A}}$ \\
\hline & Dead & 17 & $97.8 \pm 0.4$ & $410 \pm 75^{\mathrm{D}}$ & $4.58 \pm 1.01 \mathrm{BC}$ & $920 \pm 175^{\mathrm{BC}}$ & $0.028 \pm 0.018^{\mathrm{A}}$ \\
\hline \multirow[t]{2}{*}{$\mathrm{C}$} & Live & 35 & $97.3 \pm 0.7$ & $566 \pm 118^{\mathrm{BCD}}$ & $5.43 \pm 0.85^{\mathrm{AB}}$ & $1092 \pm 219^{\mathrm{ABC}}$ & $0.031 \pm 0.018^{\mathrm{A}}$ \\
\hline & Dead & 18 & $97.2 \pm 0.8$ & $503 \pm 155^{\mathrm{CD}}$ & $4.62 \pm 0.95^{\mathrm{ABC}}$ & $1110 \pm 296^{\mathrm{ABC}}$ & $0.021 \pm 0.014^{\mathrm{A}}$ \\
\hline \multirow[t]{2}{*}{$\mathrm{D}$} & Live & 10 & $96.9 \pm 0.7$ & $661 \pm 82^{\mathrm{ABC}}$ & $5.60 \pm 1.21^{\mathrm{AB}}$ & $1266 \pm 161^{\mathrm{A}}$ & $0.034 \pm 0.031^{\mathrm{A}}$ \\
\hline & Dead & 11 & $97.8 \pm 0.6$ & $400 \pm 99^{\mathrm{D}}$ & $3.95 \pm 0.78^{\mathrm{C}}$ & $880 \pm 187^{\mathrm{C}}$ & $0.018 \pm 0.011^{\mathrm{A}}$ \\
\hline \multirow[t]{2}{*}{ E } & Live & 35 & $96.7 \pm 0.9$ & $684 \pm 155^{\mathrm{AB}}$ & $5.54 \pm 1.42^{\mathrm{AB}}$ & $1240 \pm 293^{\mathrm{A}}$ & $0.031 \pm 0.030^{\mathrm{A}}$ \\
\hline & Dead & 30 & $96.4 \pm 1.3$ & $654 \pm 254 \mathrm{ABC}$ & $5.11 \pm 1.33^{\mathrm{ABC}}$ & $1358 \pm 455^{\mathrm{A}}$ & $0.021 \pm 0.011^{\mathrm{A}}$ \\
\hline F (control) & Live & 45 & $97.4 \pm 0.7$ & $609 \pm 169^{\mathrm{BC}}$ & $5.71 \pm 1.27^{\mathrm{AB}}$ & $1084 \pm 209 \mathrm{ABC}$ & $0.038 \pm 0.029^{\mathrm{A}}$ \\
\hline
\end{tabular}

Values are means \pm standard deviations among all samples

Sample groups sharing the same letter did not differ significantly in alpha diversity by Tukey's post hoc test $(p>0.05)$

in some live ZMs collected from the experimental tanks prior to any mortality events (Fig. S2). Species richness, estimated using the Chao1 index, was significantly different between live ZMs from tank $\mathrm{F}$ and dead ZMs from tank $\mathrm{E}(p<$ $0.0001)$, and with live ZMs from tank A $(p=0.004)$ (Table 1). However, no significant differences $(p>0.05)$ were observed in Simpson's evenness between live ZMs in tank F and live/dead ZMs from all other tanks (Table 1).

Regardless of the stressor (i.e., temperature or salinity), significant differences among the microbiota from live and dead ZMs in each experimental tank (A-E) and live ZMs from the control tank F were detected with Permanova $\left(R^{2}=0.153\right.$ to $0.218, p=0.001$ ) (Table $\mathrm{S} 2$ ). These results were visualized using principal coordinates analysis (Fig. 2), which explained 34.8 to $42.5 \%$ of the total variation observed.

Order-level taxonomic analyses showed that live ZMs in the control tank (F) were dominated (\% values) by Pseudomonadales (26.1 \pm 22.6$)$, Legionellales (23.3 \pm 16.3 ), Betaproteobacteriales (12.1 \pm 5.2$)$, and Flavobacteriales $(9.7$ \pm 9.2 ) (Fig. 3). Taxa that were enriched ( $\geq 3$-fold) in dead ZMs within the experimental tanks included: Aeromonadales (tanks A-E), Clostridiales (tanks A, B, D, and E), Flavobacteriales (tanks A and E) and Rhodobacterales (tanks $\mathrm{B}$ and $\mathrm{C}$ ); whereas those enriched in live ZMs within the experimental tanks included: Aeromonadales (tanks A, B, C, and D), Clostridiales (tank A), and Caedibacterales (tank B) (Fig. 3). Collectively, dead ZMs were mainly composed of Aeromonadales (29.4 \pm 25.5$)$, Flavobacteriales (16.7 \pm 13.9), Pseudomonadales (10.6 \pm 11.9$)$, and Rhodobacterales (6.4 $7 \pm 7.7)$ (Fig. 3).

The most abundant bacterial genera in live ZMs (control tank F) were Pseudomonas (20.0 \pm 21.0$)$, Legionella $(7.7 \pm$ 10.7), Chryseobacterium ( $7.7 \pm 11.8)$, "Ca. Nucleicultrix" $(3.9 \pm 6.1)$, Burkholderiaceae (other) $(3.8 \pm 2.9)$, and
Aeromonas (3.7 \pm 10.7$)$. In contrast, abundant genera in dead ZMs were comprised of Aeromonas (28.9 \pm 25.3 ), Chryseobacterium $(10.8 \pm 12.9)$, Pseudomonas $(9.4 \pm 11.1)$, Flavobacterium (5.1 \pm 8.5 ), and Rhodobacteraceae (ambiguous taxa) (3.3 \pm 3.8$)$. LEfSe analysis showed that members of the genera Aeromonas, Chryseobacterium, Flavobacterium, Acidaminobacter, Clostridiaceae 1 (other), Rhodobacteraceae (ambiguous taxa, other), Acinetobacter, Shewanella, and Clostridium sensu stricto 13 were significantly enriched (LDA score: $\geq 3.5$ ) in dead ZMs (tanks AE) compared to live ZMs (control tank F) (Fig. 4a, b). Redundancy analysis further confirmed that these enriched taxa, especially Aeromonas, were strongly associated with ZM mortality (Fig. S3).

Time-series analysis indicated a greater relative abundance of Aeromonas in dead ZMs compared to live ZMs from similar timepoints in each experimental tank (Fig. S4). Nevertheless, several live ZMs from the experimental tanks were also found to harbor Aeromonas at relative abundances similar to that of dead ZMs (Fig. S4). The relative abundance of Aeromonas in ZM feed and water samples was very low (0 to $0.29 \%)$, except for the water samples $(0.84$ to $5.04 \%)$ collected during the mortality events in tanks $\mathrm{B}$ and $\mathrm{D}$ on days 2 and 3 (Fig. S5).

\section{Proliferation of Putative Opportunistic Pathogens in Stressed ZMs}

Shotgun sequencing was performed on live and dead pooled ZMs from each tank to determine the species-level identity of microbial communities impacted by the temperature and salinity treatments. The three most abundant species in live ZMs were "Candidatus (Ca.) Thiodiazotropha endoloripes" (31.07 $\pm 4.98)$, Aeromonas caviae (21.84 \pm 6.32$)$, and Acinetobacter 

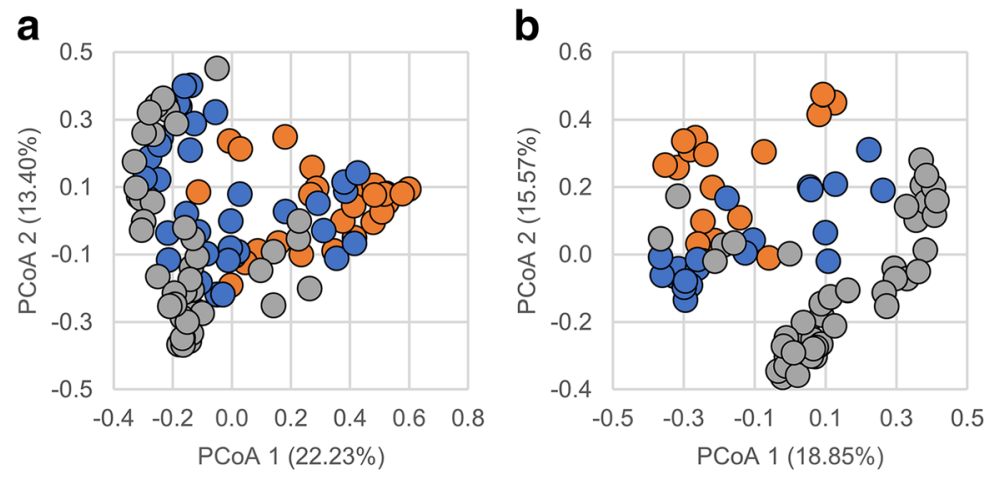

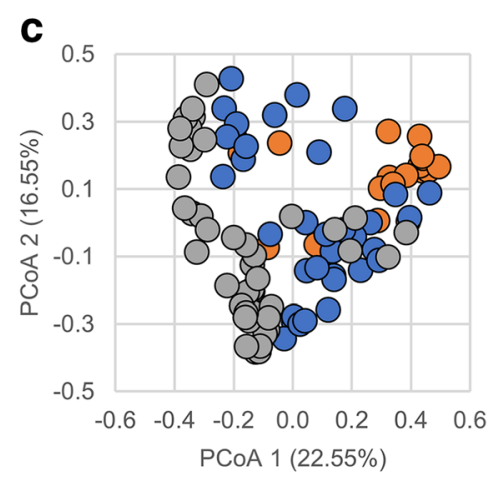

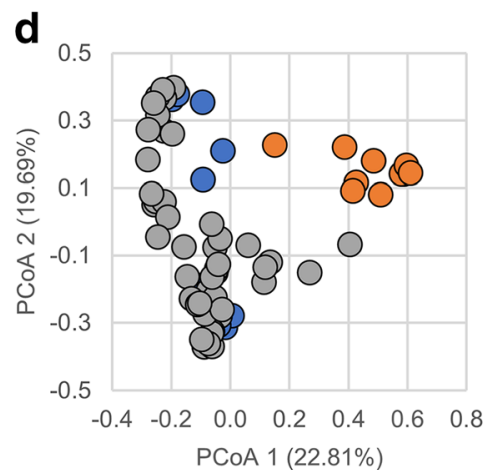

Fig. 2 Principal coordinates analysis of microbial communities associated with live and dead ZMs in each experimental tank (A-E). Live ZMs from the control tank (F) has been included in each plot for

Fig. 3 Order-level taxonomic classification of microbial communities associated with live and dead ZMs in experimental (A-E) and control tanks (F). All taxa present in $\geq 5 \%$ relative abundance in an individual ZM sample are shown in this graph
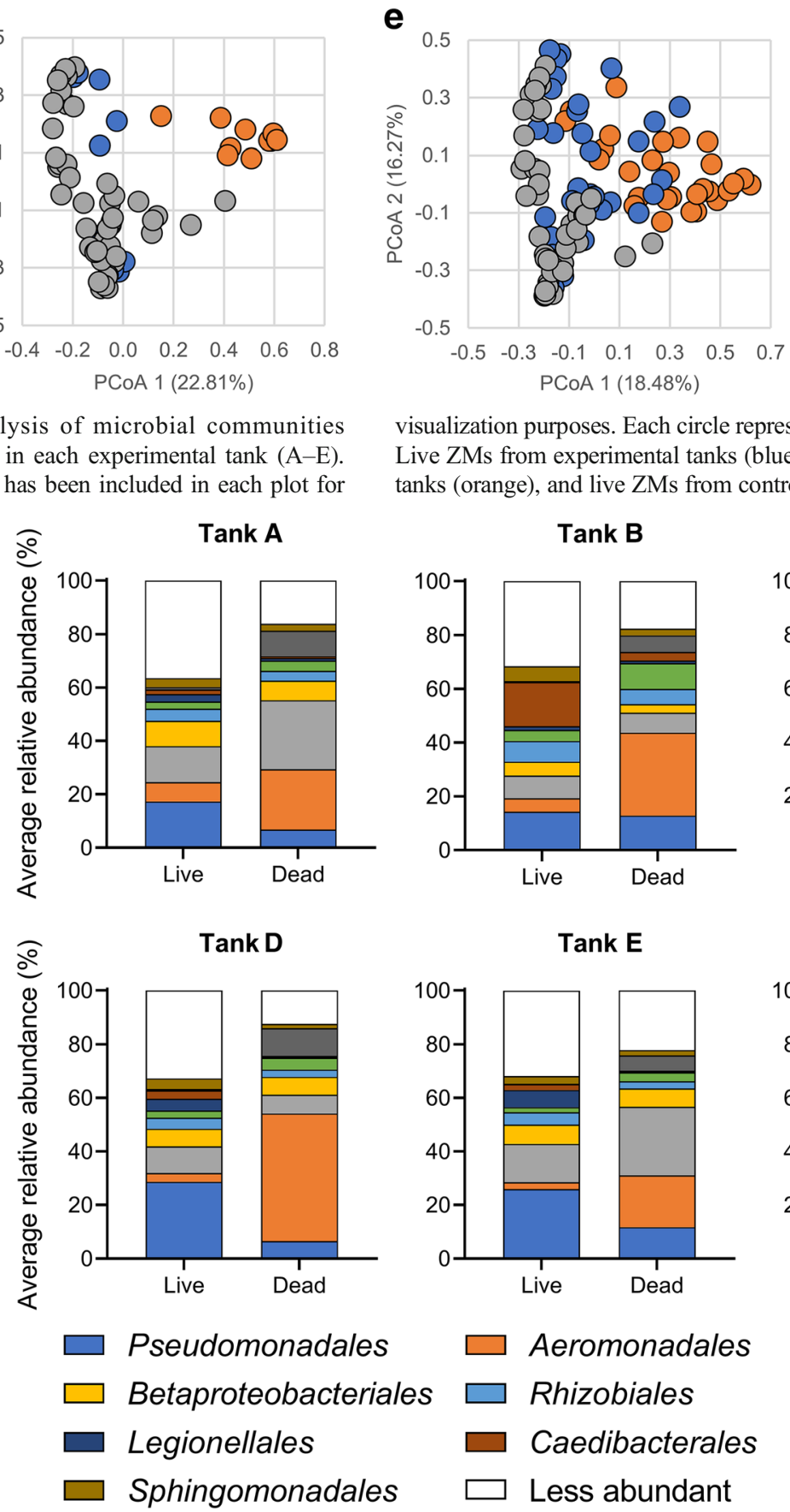

visualization purposes. Each circle represents an individual ZM. Legend: Live ZMs from experimental tanks (blue), dead ZMs from experimental tanks (orange), and live ZMs from control tank (grey)

Tank B

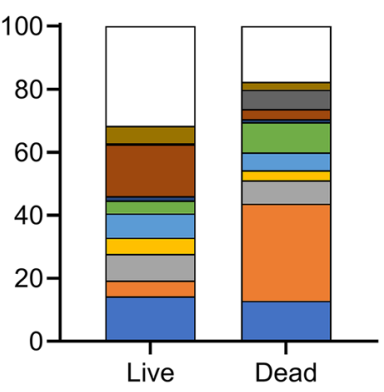

Tank E

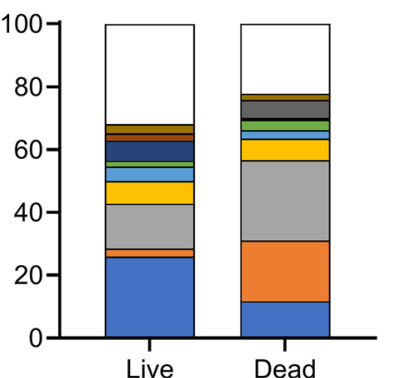

Aeromonadales

Rhizobiales

Caedibacterales

Less abundant
Tank C

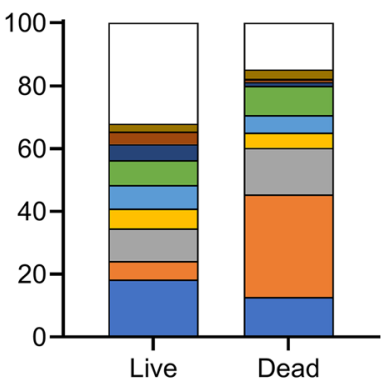

Tank F

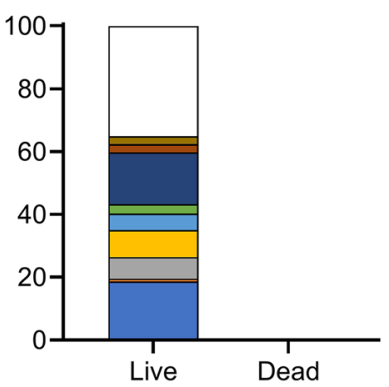

Flavobacteriales

Rhodobacterales Clostridiales 


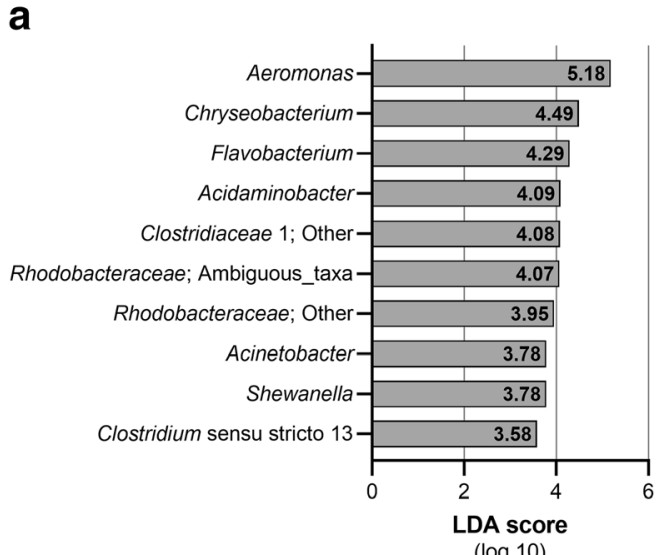

$(\log 10)$

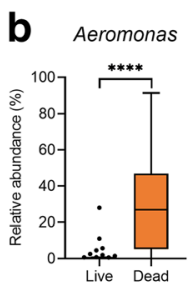

Rhodobacteracea Ambiguous_taxa

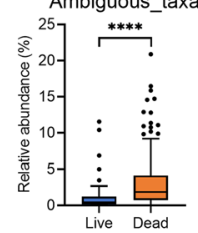

Fig. 4 a Linear discriminant analysis effect size showing taxa that were significantly enriched in dead ZMs (from experimental tanks A-E) compared to live ZMs (from control tank F). Analysis was performed at an LDA cut-off score of 3.5. b Relative abundance of taxa that were

baumannii (17.17 \pm 3.16$)$ (Fig. 5a). In contrast, the relative abundance of all three species declined significantly $(p \leq$ 0.0001) in dead ZMs (Fig. 5a). Perhaps more importantly, however, several pathogenic Aeromonas species, including A. veronii, A. sobria, A. hydrophila, A. allosaccharophila, A. salmonicidia, A. schuberti, A. media, and A. simiae were significantly $(\mathrm{p} \leq 0.0001)$ enriched in dead ZMs, compared to live mussels (Fig. 5b, Fig. S6). Aeromonas veronii was strongly associated with mortality induced by high temperature, whereas A. sobria was enriched in dead ZMs from the high salinity $\operatorname{tank}(\operatorname{tank} C)$. Other species that were overrepresented in dead ZMs included: Chryseobacterium sp. CF365, Escherichia coli, Salmonella enterica, Marinobacter sp. X15-166B, Vibrio campbellii, and Pararheinheimera texasensis (Fig. 5b). Interestingly, live ZMs from one data point (tank B, day 3) displayed a microbiota profile similar to that of dead ZMs, which was in contrast to that seen in all other live ZMs (Fig. 5, Fig. S6).

Quantitative PCR indicated that total bacterial abundance, based on the 16S rRNA gene, was significantly greater $(p<$ 0.0001 ) in tissues of dead ZMs (Fig. 6). This also corresponded with a significant 322 -fold increase $(p<$ $0.0001)$ in the abundance of the cytotoxic enterotoxin (act) gene in dead ZMs, relative to live ZMs in the control tank (Fig. 6). Moreover, live ZMs from the experimental tanks (A-E) harbored a greater abundance of act gene copies compared to those from the control tank though this observation was not statistically significant (Fig. S7).

\section{Discussion}

Results from this current study indicate that elevated temperature and salinity induced a shift in the ZM-associated microbiota, which may play an important role in its mortality. The
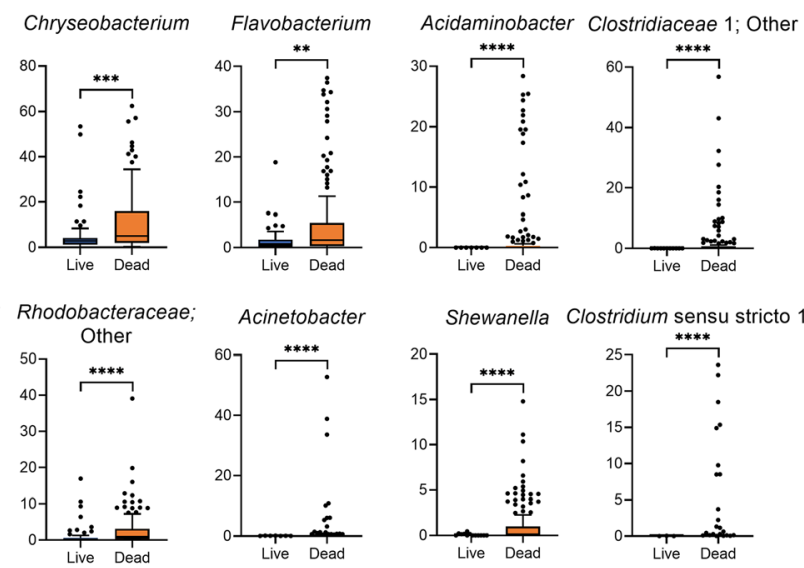

significantly enriched in dead ZMs (from experimental tanks A-E) compared to live ZMs (from control tank F). $P$ values $* * * * \leq 0.0001, * * * \leq$ $0.001, * * \leq 0.01$

mortality of ZMs in experimental tanks ranged between 53 and $100 \%$, which was concomitant with significant increases in the relative abundance of putative opportunistic pathogenic bacteria in the genera Aeromonas, Chryseobacterium, and Flavobacterium. The potential involvement of aeromonads in ZM mortality was further supported by data showing that these microbes were present in much lower relative abundance in "healthy" ZMs from the control tank, where no mortality was observed. Shotgun sequencing and qPCR analyses revealed that the relative and absolute abundances of putative pathogenic Aeromonas species, particularly A. veronii, was significantly greater in dead ZMs and some live ZMs present in the experimental tanks than in those from control tanks. While these data are suggestive of the involvement of Aeromonas in ZM mortality, we are aware that they cannot reconcile issues of cause and effect. Nevertheless, these observations are relevant as the predicted increases in water temperature and/or salinity due to anthropogenic-induced climate changes have the potential to negatively impact these widespread invasive species, and as a consequence affect ecosystem services.

Temperature appeared to have a major impact on ZM mortality (Fig. 1, Fig. S3) as was also noted in a recent study [22]. While the authors concurred that individuals could not survive exposure to water temperatures greater than $33^{\circ} \mathrm{C}$ [18], it was also reported that significant mortality was correlated with exposure time (hours) to temperatures $>25{ }^{\circ} \mathrm{C}$. Similarly, our results show a clear correlation between exposure degree hours $>25{ }^{\circ} \mathrm{C}$ and mortality (Table S2). Both high temperature conditions examined (tanks B and D) resulted in severe and rapid mortality relative to what was seen in other tanks. The relatively higher mortality rate in tank D (high temperature) compared with tank B (high temperature + high salinity) suggests that mortality was somewhat modulated by conditioning to another stressor. While the temperature in the 


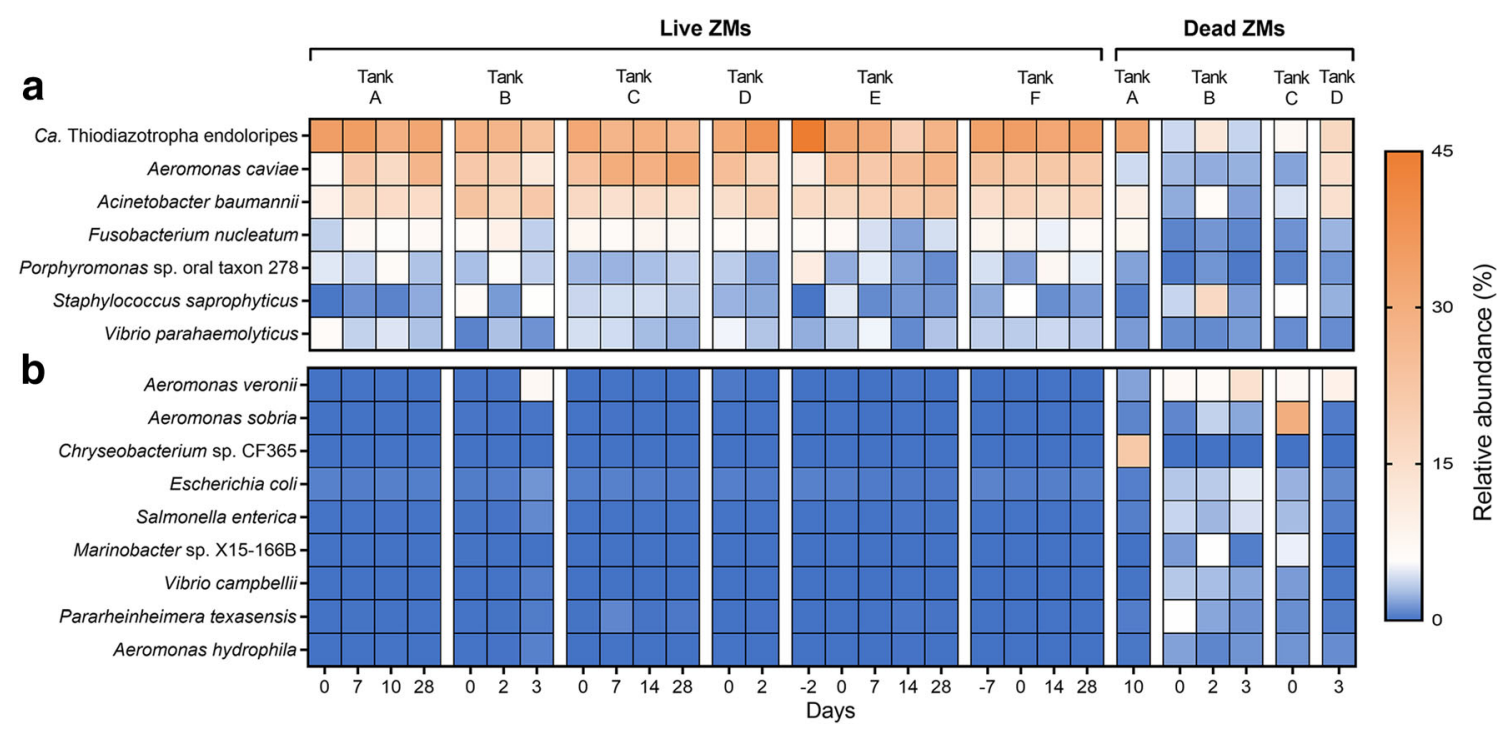

Fig. 5 Shotgun sequence analysis of select live and dead ZMs from different tanks (a) Most abundant bacterial species ( $\geq 5 \%$ relative abundance) in live ZMs, and (b) Bacterial species that increased $\geq 5$-fold in relative abundance in dead ZMs compared to live ZMs

medium tank (tank E) was about half $\left(9{ }^{\circ} \mathrm{C}\right.$ vs. $\left.15^{\circ} \mathrm{C}\right)$ of that used in the high temperature tanks (B and $\mathrm{D}$ ), the mortality was proportionally lower. Interestingly, it also appears that consistently high temperatures have a greater impact on ZM mortality compared to fluctuating temperatures, as the alternating temperature tank $(\mathrm{A})$, which sees similarly high acute temperatures as the high temperature conditions does not have the same extent of mortality as did the high temperature conditions. Along similar lines, a recent study done using Tigriopus californicus reported that daily degree-hours best explained temperature wave induced mortality in this marine copepod [17].

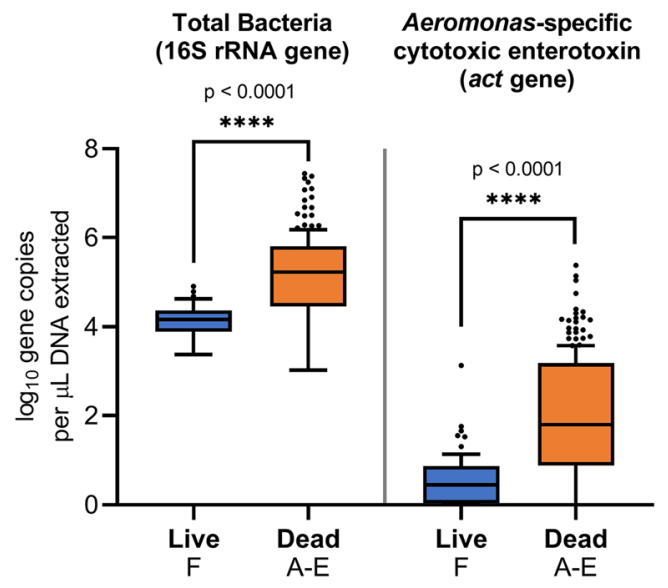

Fig. 6 Quantification of 16S rRNA (total bacteria) and act (Aeromonasspecific cytotoxic enterotoxin) gene in dead ZMs (from experimental tanks A-E) and live ZMs (from control tank F). Tukey's HSD post-hoc test. On the boxplots, the centerlines show the medians, the bottom and upper limits indicate the 25th and 75th percentiles and the whiskers encompass the $10-90$ percentile range. $P$ value $* * * * \leq 0.0001$
Here, we also show that microbial diversity, as revealed by the Shannon index, was significantly reduced in dead ZMs from tanks B (high temperature + high salinity) and D (high temperature) relative to live ones in the control tank (Table 1). Moreover, dead ZMs were less diverse compared to live ZMs in each experimental tank (Table 1). Notably, a reduction in microbial diversity was also observed in some live ZMs collected from the experimental tanks prior to any mortality events (Fig. S2). It is a widely held concept among microbial ecologists that species diversity is strongly and positively correlated with ecosystem stability, and that high microbial diversity reduces perturbation-induced community decline or collapse [41, 42]. Lower microbial diversity has also been linked with impaired health status in bivalve species, including the Pacific oyster [43]. Furthermore, principal coordinates analysis revealed that microbial communities associated with dead ZMs in the experimental tanks clustered separately from those in live ZMs from the control tank (Fig. 2). Taken together, these results show that ZM mortality (or health status) is strongly associated with shifts in microbial community structure, although cause and effect as not been rigorously established.

Several mechanisms have been proposed by which stressinduced shifts in microbiota composition may deleteriously affect host fitness [44, 45]. For example, in humans and in advanced lower animals, it is well known that gut microbiota play a critical role in enhancing the digestive efficiency of complex food sources and in producing nutrients that are not host provided [46]. This is facilitated by microbial production of novel enzymes that the host is not capable of producing, or by increasing the abundance and (or) activity of enzymes critical to digestion [44, 45]. Hence, stress-induced alterations in gut microbiota may affect the metabolic costs and benefits 
received by the hosts. In addition to fulfilment of nutritional needs, a diverse and established microbiota also protects the host from invasion and colonization by pathogens via the secretion of antimicrobials, production of cell signaling molecules, the regulation of host genes, monopolization of resources, or by filling critical surface niches [44, 47, 48]. It is thought that disruption of the resident microbiota could reduce colonization resistance by opening up ecological niches in the gut for pathogens and/or by eliminating/reducing the abundances of gut bacteria that inhibit the growth of pathogens [45].

Members of the genus Aeromonas were strongly associated with dead ZMs (Fig. 4, Fig. S3). Subsequent species-level resolution data obtained by using shotgun sequencing indicated that A. caviae was the dominant Aeromonas species within live "healthy" ZMs. Moreover, ZM mortality was related to the decline of this bacterium, and a concomitant significant increase in the abundance of other Aeromonas species, especially A. veronii and A. sobria (Fig. 5, Fig. S6). A similar observation was also made with live ZMs collected from an experimental tank, suggesting that these mussels were on a trajectory towards death (Fig. S6). The contribution of A. caviae to host fitness is not known, but it appears that is a part of the microbial flora of healthy ZMs. These results also underscore the importance of examining microbial taxa at finer taxonomic resolution (species-level). Previous studies have demonstrated that activity of A. media, mediated by bacteriocins, was protective against several opportunistic pathogens of Pacific oysters, including other pathogenic Aeromonas strains $[49,50]$. The authors later reported that antagonist activity in A. media was dependent on the production of indole (2,3 benzopyrrole) by the bacterium [51].

Our qPCR analyses indicated that there was a 322 -fold increase in the abundance of the act gene in dead ZMs, relative to that found in live ZMs from the control tank, further confirming the proliferation of putative pathogenic Aeromonas species (Fig. 6). The act gene, which has been detected in Aeromonas isolates from fish [52] and mussels [53], encodes a secreted cytotoxic enterotoxin, which possesses hemolytic, cytotoxic, and enterotoxic activities. This toxin, which is among the most potent virulence factors in Aeromonas species, has been shown to induce lethality in a mouse model [54-56]. Our findings are in agreement with those from previous studies which demonstrated that Aeromonas spp. strain isolated from dead ZMs, such as A. veronii, A. jandaei, and A. media, were pathogenic to "healthy" live ZMs, and when re-inoculated resulted in mortality [57, 58], in many ways fulfilling Koch's postulates

Lastly, several of these putative pathogens, including Aeromonas, were consistently detected in relatively low abundance in "non-stressed" ZMs from the control tank (Fig. 5, Fig. S4), suggesting that the natural microbiota in ZM likely act as the source of opportunistic pathogens that become less attenuated during stress events. More importantly, however, while the relative abundance of Aeromonas in the microalgae feed and tank water samples was very low, water and ZM tissue samples that were collected during mass mortality events in tanks B and D (Fig. S5) had exceedingly high concentrations of Aeromonas spp. strains. Based on these results, our data suggest that the likely source of these putative pathogens was the host's natural microbiota and not those from an external environmental source.

Despite the strong association of Aeromonas spp. strain with dead ZMs, our study was not designed to separate out cause from effect. Establishment of this causal sequence must await more detailed microbial transplant studies and possibly the establishment of near axenic lines of ZMs. Moreover, we are acutely aware of the statistical limitations of this study, mainly imparted by space-induced limitations to sufficient replication in the BSL-2 invasive species containment facility. Due to this reason, readers should be cautious in trying to extend these results to the natural world - beyond this specific experiment." That said, however, the very large differences in stressor-induced mortality in experimental tanks were quite obvious.

\section{Conclusions}

Our findings strongly suggest that environmental stressors, especially elevated temperature, have the potential to induce ZM mortality. The observed changes within bacterial community structure and diversity in dead ZMs may be due to direct or indirect effects. Direct effects include stressor-induced changes to the growth rate of specific bacterial taxa, including putative pathogens. In contrast indirect effects may be due to stressor-induced decline of commensal bacteria, or to multiple synergistic effects on microbiota and host metabolic processes. Independent of cause, the negative effects of stressors on ZMs likely include increased relative growth rates of putative pathogens, reduced health benefits, and/or decreased immune function. Results of this study will be useful for understanding $\mathrm{ZM}$ biology, as well as the identification of abiotic and biotic factors that influence the fitness of this highly invasive bivalve species.

Supplementary Information The online version contains supplementary material available at https://doi.org/10.1007/s00248-020-01642-2.

Acknowledgements The authors wish to thank Jonah Bacon and Nicholas Jacob for their assistance. This work was carried out, in part, by using computing resources at the University of Minnesota Supercomputing Institute.

Funding Funding for this study was provided by the Minnesota Aquatic Invasive Species Research Center, through the Minnesota Environment and Natural Resources Trust Fund, as recommended by the Legislative- 
Citizen Commission on Minnesota Resources, and by the Minnesota Agricultural Experiment Station.

\section{Compliance with Ethical Standards}

Conflict of interest The authors declare that they have no conflict interest.

Open Access This article is licensed under a Creative Commons Attribution 4.0 International License, which permits use, sharing, adaptation, distribution and reproduction in any medium or format, as long as you give appropriate credit to the original author(s) and the source, provide a link to the Creative Commons licence, and indicate if changes were made. The images or other third party material in this article are included in the article's Creative Commons licence, unless indicated otherwise in a credit line to the material. If material is not included in the article's Creative Commons licence and your intended use is not permitted by statutory regulation or exceeds the permitted use, you will need to obtain permission directly from the copyright holder. To view a copy of this licence, visit http://creativecommons.org/licenses/by/4.0/.

\section{References}

1. Hebert PDN, Muncaster BW, Mackie GL (1989) Ecological and genetic studies on Dreissena polymorpha (Pallas): a new mollusc in the Great Lakes. Can J Fish Aquat Sci 46:1587-1591. https://doi. org/10.1139/f89-202

2. Benson AJ (2014) Chronological history of zebra and quagga mussels (Dreissenidae) in North America, 1988-2010. Chapter 1. In: Nalepa TF, Schloesser DW (eds) Quagga and zebra mussels: Biology, impacts, and control. CRC Press, Boca Raton, pp 9-31

3. Churchill CJ, Hoeinghaus DJ, La Point TW (2017) Environmental conditions increase growth rates and mortality of zebra mussels (Dreissena polymorpha) along the southern invasion front in North America. Biol Invasions 19:2355-2373. https://doi.org/10. 1007/s10530-017-1447-8

4. Colorado Parks and Wildlife (2019) State aquatic nuisance species (ANS) program, summary for Colorado legislators per SB 08-226. https://spl.cde.state.co.us/artemis/nrserials/nr1492internet/ nr14922019internet.pdf

5. Karatayev AY, Burlakova LE, Padilla DK (2002) Impacts of zebra mussels on aquatic communities and their role as ecosystem engineers. In: Leppäkoski E, Gollasch S, Olenin S (eds) Invasive Aquatic Species of Europe. Distribution, Impacts and Management. Springer Netherlands, Dordrecht, pp 433-446

6. Ackerman JD, Sim B, Nichols SJ, Claudi R (2008) A review of the early life history of zebra mussels (Dreissena polymorpha ): comparisons with marine bivalves. Can J Zool 72:1169-1179. https:// doi.org/10.1139/z94-157

7. Ludyanskiy ML, Mcdonald D, Macneill D (1993) Impact of the zebra mussel, bivalve invader a Dreissena polymorpha is rapidly colonizing hard surfaces throughout waterways of the United States and Canada. Bioscience 43:533-544

8. Lavrentyev PJ, Gardner WS, Yang L (2000) Effects of the zebra mussel on nitrogen dynamics and the microbial community at the sediment-water interface. Aquat Microb Ecol 21:187-194. https:// doi.org/10.3354/ame021187

9. Higgins SN, Vander ZMJ (2010) What a difference a species makes: a meta-analysis of dreissenid mussel impacts on freshwater ecosystems. Ecol Monogr 80:179-196. https://doi.org/10.1890/091249.1
10. Ozersky T, Evans DO, Barton DR (2012) Invasive mussels alter the littoral food web of a large lake: stable isotopes reveal drastic shifts in sources and flow of energy. PLoS One 7:e51249. https://doi.org/ 10.1371/journal.pone.0051249

11. Ward JM, Ricciardi A (2010) Community-level effects of cooccurring native and exotic ecosystem engineers. Freshw Biol 55: 1803-1817. https://doi.org/10.1111/j.1365-2427.2010.02415.x

12. Stefanoff S, Vogt RJ, Howell T, Sharma S (2018) Phytoplankton and benthic algal response to ecosystem engineers and multiple stressors in the nearshore of Lake Huron. J Great Lakes Res 44: 447-457. https://doi.org/10.1016/j.jglr.2018.02.009

13. Fera SA, Rennie MD, Dunlop ES (2017) Broad shifts in the resource use of a commercially harvested fish following the invasion of dreissenid mussels. Ecology 98:1681-1692. https://doi.org/10. 1002/ecy. 1836

14. Haag WR, Warren ML (2008) Effects of severe drought on freshwater mussel assemblages. Trans Am Fish Soc 137:1165-1178. https://doi.org/10.1577/t07-100.1

15. McDowell WG, Sousa R (2019) Mass mortality events of invasive freshwater bivalves: current understanding and potential directions for future research. Front Ecol Evol 7. https://doi.org/10.3389/fevo. 2019.00331

16. McDowell WG, McDowell WH, Byers JE (2017) Mass mortality of a dominant invasive species in response to an extreme climate event: implications for ecosystem function. Limnol Oceanogr 62: 177-188. https://doi.org/10.1002/lno.10384

17. Siegle MR, Taylor EB, O'Connor MI (2018) Prior heat accumulation reduces survival during subsequent experimental heat waves. $\mathrm{J}$ Exp Mar Biol Ecol 501:109-117. https://doi.org/10.1016/j.jembe. 2018.01.012

18. Spidle AP, May B, Mills EL (1995) Limits to tolerance of temperature and salinity in the quagga mussel (Dreissena bugensis) and the zebra mussel (Dreissena polymorpha). Can J Fish Aquat Sci 52: 2108-2119. https://doi.org/10.1139/f95-804

19. Kennedy VS, Magee JA, Wright DA et al (2006) Effect of salinity and temperature on survival and development of young zebra (Dreissena polymorpha) and Quagga (Dreissena bugensis) mussels. Estuaries 19:619. https://doi.org/10.2307/1352522

20. Kilgour BW, Mackie GL, Baker MA, Keppel R (2006) Effects of salinity on the condition and survival of zebra mussels (Dreissena polymorpha). Estuaries 17:385. https://doi.org/10.2307/1352671

21. Mathai PP, Magnone P, Dunn HM, Sadowsky MJ (2020) Water and sediment act as reservoirs for microbial taxa associated with invasive dreissenid mussels. Sci Total Environ 703:134915. https:// doi.org/10.1016/j.scitotenv.2019.134915

22. White JD, Hamilton SK, Sarnelle O (2015) Heat-induced mass mortality of invasive zebra mussels (Dreissena polymorpha) at sublethal water temperatures. Can J Fish Aquat Sci 72:1221-1229. https://doi.org/10.1139/cjfas-2015-0064

23. Strayer DL, Smith LC (1993) Distribution sf the zebra mussel (Dreissena polymorphn) in estuaries and brackish water. Zebra mussels: biology, impacts, and control. Lewis Publishers, Boca Raton

24. Gohl DM, Vangay P, Garbe J, MacLean A, Hauge A, Becker A, Gould TJ, Clayton JB, Johnson TJ, Hunter R, Knights D, Beckman KB (2016) Systematic improvement of amplicon marker gene methods for increased accuracy in microbiome studies. Nat Biotechnol 34:942-949. https://doi.org/10.1038/nbt.3601

25. Caporaso JG, Kuczynski J, Stombaugh J, Bittinger K, Bushman FD, Costello EK, Fierer N, Peña AG, Goodrich JK, Gordon JI, Huttley GA, Kelley ST, Knights D, Koenig JE, Ley RE, Lozupone CA, McDonald D, Muegge BD, Pirrung M, Reeder J, Sevinsky JR, Turnbaugh PJ, Walters WA, Widmann J, Yatsunenko T, Zaneveld J, Knight R (2010) QIIME allows analysis of highthroughput community sequencing data. Nat Methods 7:335-336 
26. Bolger AM, Lohse M, Usadel B (2014) Trimmomatic: a flexible trimmer for Illumina sequence data. Bioinformatics 30:2114-2120. https://doi.org/10.1093/bioinformatics/btu170

27. Masella AP, Bartram AK, Truszkowski JM, Brown DG, Neufeld JD (2012) PANDAseq: paired-end assembler for illumina sequences. BMC Bioinf 13:1-7. https://doi.org/10.1186/1471-210513-31

28. Aronesty E (2013) Comparison of sequencing utility programs. Open Bioinforma J 7:1-8. https://doi.org/10.2174/ 1875036201307010001

29. Edgar RC, Haas BJ, Clemente JC, Quince C, Knight R (2011) UCHIME improves sensitivity and speed of chimera detection. Bioinformatics 27:2194-2200. https://doi.org/10.1093/ bioinformatics/btr381

30. Wang Q, Garrity GM, Tiedje JM, Cole JR (2007) Naïve Bayesian classifier for rapid assignment of rRNA sequences into the new bacterial taxonomy. Appl Environ Microbiol 73:5261-5267. https://doi.org/10.1128/AEM.00062-07

31. Caporaso JG, Bittinger K, Bushman FD, DeSantis TZ, Andersen GL, Knight R (2009) PyNAST: a flexible tool for aligning sequences to a template alignment. Bioinformatics 26:266-267. https://doi.org/10.1093/bioinformatics/btp636

32. Quast C, Pruesse E, Yilmaz P, Gerken J, Schweer T, Yarza P, Peplies J, Glöckner FO (2013) The SILVA ribosomal RNA gene database project: Improved data processing and web-based tools. Nucleic Acids Res 41:590-596. https://doi.org/10.1093/nar/ gks 1219

33. Edgar RC (2010) Search and clustering orders of magnitude faster than BLAST. Bioinformatics 26:2460-2461. https://doi.org/10. 1093/bioinformatics/btq461

34. Anderson MJ (2001) A new method for non-parametric multivariate analysis of variance. Austral Ecol 26:32-46. https://doi.org/10. 1111/j.1442-9993.2001.01070.pp.x

35. Oksanen J, Blanchet GF, Friendly M, Kindt R, Legendre P, McGlinn D, Minchin PR, O'Hara R, Simpson GL, Solymos P, et al. (2017) vegan: Community Ecology Package. R package version 2.4-4. https://CRAN.R-project.org/package=vegan

36. Anderson MJ, Ellingsen KE, McArdle BH (2006) Multivariate dispersion as a measure of beta diversity. Ecol Lett 9:683-693. https:// doi.org/10.1111/j.1461-0248.2006.00926.x

37. Segata N, Izard J, Waldron L, Gevers D, Miropolsky L, Garrett WS, Huttenhower C (2011) Metagenomic biomarker discovery and explanation. Genome Biol 12:R60. https://doi.org/10.1186/gb-201112-6-r60

38. Wood DE, Salzberg SL (2014) Kraken: ultrafast metagenomic sequence classification using exact alignments. Genome Biol 15:R46. https://doi.org/10.1186/gb-2014-15-3-r46

39. Muyzer G, de Waal EC, Uitterlinden AG (1993) Profiling of complex microbial populations by denaturing gradient gel electrophoresis analysis of polymerase chain reaction-amplified genes coding for 16S rRNA. Appl Environ Microbiol 59:695 LP-695700

40. Kingombe CI, Huys G, Tonolla M et al (1999) PCR detection, characterization, and distribution of virulence genes in Aeromonas spp. Appl Environ Microbiol 65:5293 LP-5295302

41. Lozupone CA, Stombaugh JI, Gordon JI, Jansson JK, Knight R (2012) Diversity, stability and resilience of the human gut microbiota. Nature 489:220-230. https://doi.org/10.1038/nature11550

42. Sommer F, Anderson JM, Bharti R, Raes J, Rosenstiel P (2017) The resilience of the intestinal microbiota influences health and disease. Nat Rev Microbiol 15:630-638. https://doi.org/10.1038/nrmicro. 2017.58
43. Lokmer A, Mathias Wegner K (2015) Hemolymph microbiome of Pacific oysters in response to temperature, temperature stress and infection. ISME J 9:670-682. https://doi.org/10.1038/ismej.2014. 160

44. Pierce ML, Ward JE (2018) Microbial ecology of the Bivalvia, with an emphasis on the family Ostreidae. J Shellfish Res 37:793-806. https://doi.org/10.2983/035.037.0410

45. Sepulveda J, Moeller AH (2020) The effects of temperature on animal gut microbiomes. Front Microbiol 11:384. https://doi.org/ $10.3389 /$ fmicb.2020.00384

46. Rowland I, Gibson G, Heinken A, Scott K, Swann J, Thiele I, Tuohy K (2018) Gut microbiota functions: metabolism of nutrients and other food components. Eur J Nutr 57:1-24. https://doi.org/10. 1007/s00394-017-1445-8

47. Sassone-Corsi M, Raffatellu M (2015) No Vacancy: How Beneficial Microbes Cooperate with Immunity To Provide Colonization Resistance to Pathogens. J Immunol 194:4081 LP4084087. https://doi.org/10.4049/jimmunol.1403169

48. Buffie CG, Pamer EG (2013) Microbiota-mediated colonization resistance against intestinal pathogens. Nat Rev Immunol 13:790 801. https://doi.org/10.1038/nri3535

49. Gibson LF, Woodworth J, George AM (1998) Probiotic activity of Aeromonas media on the Pacific oyster, Crassostrea gigas, when challenged with Vibrio tubiashii. Aquaculture 169:111-120. https://doi.org/10.1016/S0044-8486(98)00369-X

50. Gibson LF (1998) Bacteriocin activity and probiotic activity of Aeromonas media. J Appl Microbiol 85:243S-248S. https://doi. org/10.1111/j.1365-2672.1998.tb05304.x

51. Lategan MJ, Booth W, Shimmon R, Gibson LF (2006) An inhibitory substance produced by Aeromonas media A199, an aquatic probiotic. Aquaculture 254:115-124. https://doi.org/10.1016/j. aquaculture.2005.11.019

52. Nawaz M, Khan SA, Khan AA, Sung K, Tran Q, Kerdahi K, Steele R (2010) Detection and characterization of virulence genes and integrons in Aeromonas veronii isolated from catfish. Food Microbiol 27:327-331. https://doi.org/10.1016/j.fm.2009.11.007

53. Hossain S, Wickramanayake MVKS, Dahanayake PS, Heo G-J (2020) Species identification, virulence markers and antimicrobial resistance profiles of Aeromonas sp. isolated from marketed hardshelled mussel (Mytilus coruscus) in Korea. Lett Appl Microbiol 70:221-229. https://doi.org/10.1111/lam.13266

54. Chopra AK, Houston CW, Peterson JW, Jin G-F (1993) Cloning, expression, and sequence analysis of a cytolytic enterotoxin gene from Aeromonas hydrophila. Can J Microbiol 39:513-523. https:// doi.org/10.1139/m93-073

55. Xu X-J, Ferguson MR, Popov VL et al (1998) Role of a Cytotoxic Enterotoxin in Aeromonas-Mediated Infections: Development of Transposon and Isogenic Mutants. Infect Immun 66:3501 LP3503509. https://doi.org/10.1128/IAI.66.8.3501-3509.1998

56. Ferguson MR, Xu XJ, Houston CW et al (1997) Hyperproduction, purification, and mechanism of action of the cytotoxic enterotoxin produced by Aeromonas hydrophila. Infect Immun 65:4299 LP4294308

57. Gu JD, Mitchell R (2002) Indigenous microflora and opportunistic pathogens of the freshwater zebra mussel, Dreissena polymorpha. Hydrobiologia 474:81-90. https://doi.org/10.1023/A: 1016517107473

58. Maki JS, Patel G, Mitchell R (1998) Experimental pathogenicity of Aeromonas spp. for the Zebra mussel, Dreissena polymorpha. Curr Microbiol 36:19-23. https://doi.org/10.1007/s002849900273 